\title{
Clinical Studies on Treatment of Long Bone Fracture by the Use of Plate Rod Construct
}

\author{
G. U. Yadav*, L. B. Sarkate and D. U. Lokhande \\ Department of Surgery and Radiology, Mumbai Veterinary College Parel, \\ Mumbai-400012, India \\ Maharashtra Animlal and Fishery University Nagpur \\ *Corresponding author
}

Keywords

Long Bone

Fracture, Plate Rod

Construct

Article Info

Accepted:

18 March 2021

Available Online:

10 April 2021

\section{A B S T R A C T}

Eight cases of long bone fractures of femur and humerus were treated with plate rod construct, whereas, The preoperative anterio- posterior (AP) and lateral radiographs (L) of fractured limb were taken in each case for the diagnosis of fracture following light sedation. Preoperatively the animals were kept off food for 18 hours and withheld of water for 12 hours. Atropine sulphate $(0.4 \mathrm{mg} / \mathrm{kg})$ and dexamethasone $(0.5 \mathrm{mg} / \mathrm{kg})$ was given half an hour prior to surgery. Diazepam $(0.2 \mathrm{mg} / \mathrm{kg})$ was administered intravenously, 10 minutes prior to induction of general anaesthesia with thiopentone sodium (15 $\mathrm{mg} / \mathrm{kg}$ body weight) followed by maintained with isoflurane $(1.5-2.0 \%)$. the plate rod construct was applied by craniolateral approach in case of humerus and femur. The dogs showed excellent wound healing and none of the dog showed any complications after surgery. The period of $12.8 \pm 2.3$ days was required to attain normal gait for all the dogs, Normal shape of limb after fracture healing was observed, time required for clinical healing of fracture: was $62.25 \pm 2.25$ days, time required to attaining full mobility: was $58.75 \pm$ 6.67 days

\section{Introduction}

Plate rod technique of fracture fixation is based on biological osteosynthesis and is a combination of intramedullary pin and dynamic compression plate (Stifler, 2004). This technique was found useful for repair of comminuted fractures of femur and humerus. Roul (1998) stated that plate rod construct increases the rigidity of bone plate by combining it with intramedullary pin and thereby it neutralizes bending, rotational and compressive forces. Dynamic compression plate is weaker in bending while intramedullary pin resists the bending force and therefore plate rod construct fixation allows faster use of limb and maintains the normal muscle mass of fractured limb. The 
plate rod construct gives complete rigidity to the fractured bone. This combination avoids the plate fatigue, premature breakage of plate by reducing strain and increases the plate life by 10 times (Konning et al., 2008). The present study deals with clinical study of cases of long bone fracture treated with plate rod construct.

\section{Materials and Methods}

The present study was conducted on eight clinical cases in canine having fractures of long bones, presented to the Department of Surgery, Mumbai Veterinary College, Parel and Bai Sakarbai Dinshaw Petit Hospital for Animals, affiliated animal hospital with the College.

\section{X-Ray examination}

The preoperative radiographs of fractured limb in anterio-posterior and lateral position were taken in each case for the diagnosis of fracture following light sedation and each radiograph was evaluated for the type of fracture as well as for damage in the surrounding tissue.

\section{Preoperative preparation of patients}

Preoperatively animals were kept off food for 18 hours and water was withheld for 12 hours. Fluid therapy Ringers Lactate solution@60 $\mathrm{ml} / \mathrm{kg}$ body weight of dog was administered intravenously prior to surgery. Similarly, prophylactic cefotaxime $(25 \mathrm{mg} / \mathrm{kg})$ and antinflammatory meloxicam $(0.2-0.3 \mathrm{mg} / \mathrm{kg}$.) was administered intramuscularly an hour prior to surgery.

\section{Anaesthesia}

All the orthopaedic surgeries were performed under general anaesthesia using isoflurane inhalation anaesthesia by giving atropine sulphate $(0.04 \mathrm{mg} / \mathrm{kg})$ and dexamethasone $(0.5$ $\mathrm{mg} / \mathrm{kg}$ ) subcutaneously half an hour prior to surgery. Diazepam $(0.2 \mathrm{mg} / \mathrm{kg}) \quad$ was administered intravenously, 10 minutes prior to induction of general anaesthesia with Thiopentone sodium $(15 \mathrm{mg} / \mathrm{kg})$. Following smooth induction of anaesthesia, the surgical anaesthesia was maintained throughout the duration of surgery using isoflurane (1.5 - 2.0 $\%$ ) inhalation anaesthesia.

\section{Surgical procedure}

In this group, the plate rod construct was used for the repair of femoral and humeral fractures in dogs. After anatomical dissection the intramedullary pin of approximately $25-40 \%$ of the diameter of the medullary canal was selected. The Steinman pin or K-wire of $2 \mathrm{~mm}$ or $2.5 \mathrm{~mm}$ size pin was inserted in a retrograde fashion till it comes out at the top of the skin surface and then the pin was moved down into the distal femoral or humoral fragment. The stainless steel bone plate of $2 \mathrm{~mm}$ thick and appropriate length with $2.7-3.5 \mathrm{~mm}$ hole (DCP) size was selected, and applied on the tensile surface of the bone. Two holes one each at upper and lower extremity were drilled in cis and trans cortices with appropriate sized drill bit. During drilling chilled sterile normal saline was sprinkled to avoid heat necrosis of bone. Screw length was measured by depth gauge and then placed through the drilled hole (Plate 50). Following tapping the holes most proximal and distal screws of appropriate size and length were inserted first so as to avoid the intramedullary pin and engage both near and far cortices. Later remaining bicortical screws were fixed.

\section{Clinical parameters}

In all the cases of all groups the following parameters were studied,

Wound healing: Wound healing was evaluated up to twenty days after surgery, 
Gait on day $1^{\text {st }}, 10,20,30,60$ post operatively,

Change in shape of limb on day $10,20,30^{\text {th }}$ and $60^{\text {th }}$ day,

Time required for clinical healing of fracture was noted and

Time required to attaining full mobility, was recorded

\section{Results and Discussion}

A total of 8 clinical cases of dogs of long bone fractures were treated with plate rod construct, which are as follows

\section{X- Ray examination}

The pre-operative anterio-posterior (AP) and lateral radiographs (L) of affected limb were taken in each case, for the diagnosis of type of fracture following light sedation. Each radiograph was evaluated for the type of fracture as well as for damage to the surrounding tissue. The radiography helped in determining the size of affected bone, type of fracture and selection of suitable equipment and technique for fracture fixation before performing the surgical intervention. The corrective orthopaedic procedures to be adopted for the repair of each fracture was properly planned based on the radiographic examination of the affected bone. The digital radiography facility in the hospital provided measurements of affected bone as well as normal bone. This facility gave additional idea about the length (in $\mathrm{mm}$ ) and thickness (in $\mathrm{mm}$ ) of bone useful for selection of proper sized bone plate and bone screws for fracture fixation. The measurement of length and thickness of fractured and normal bone helped in selection of implant of proper size for fracture repair. Depending upon the severity of combination, the fractures were classified. Pre-operative radiography had given an idea about the choice of technique to be used for the repair of fracture and thus it helped the surgeon to plan the surgery in a systemic way for better outcome. Bhalerao (2010), Coutinho (2012) and Chavan (2013) performed preoperative radiography for the evaluation of fracture as well as for selecting the proper technique of fracture repair.

\section{Planning for fracture repair}

In the present study, simple, comminuted and oblique fractures in hyperactive animals were operated with plate rod construct. Bhalerao (2010) used plate rod construct in similar types of fractures.

\section{Preparation of patients}

Proper care was taken to withhold water for 12 hours and food for 18 hours prior to surgery, so as to prevent untoward complications during induction and maintenance of anaesthesia during surgery. Kaur (2011) advised withholding of food for 12 hours and water for 4 hours before performing surgery. Withholding of food for 18 hours and water for 12 hours prior to surgery usually helped in preventing the anaesthetic complications like regurgitation, aspiration pneumonia and contamination of surgical field with faeces and urine Newton and Nanumaker (1985), Rani (2008).Ringers Lactate solution $(60 \mathrm{ml} / \mathrm{kg})$ depending upon the weight of dog was administered intravenously prior to surgery so as to maintain the hydration. Pre-operatively prophylactic antibiotic Cefotaxime $(25 \mathrm{mg} / \mathrm{kg})$ and antinflammatory meloxicam (0.2-0.3 $\mathrm{mg} / \mathrm{kg}$ ) intramuscularly were administered 6 hours prior to surgery.

\section{Anaesthesia}

All the orthopaedic surgeries in all the groups were performed under general anaesthesia using isoflurane. Pre-medication with atropine 
sulphate@ 0.04 mg/kg and dexamethasone @ $0.5 \mathrm{mg} / \mathrm{kg}$ body weight subcutaneously followed by intravenous injection of Diazepam $(0.2 \mathrm{mg} / \mathrm{kg})$ provided smooth sedation in all the dogs. General anaesthesia induced by intravenous injection of thiopentone sodium was smooth in all the dogs. Following smooth induction, the surgical anaesthesia was maintained with isoflurane $(1.5-2.0 \%)$ anaesthesia. This anaesthetic protocol was found most suitable for performing the orthopaedic procedures and no complications were recorded in any animals during surgery. In the present study, combination of diazepam and thiopentone provided the excellent muscle relaxation, while Isoflurane produced excellent and safe surgical anaesthesia during the course of surgery. The recovery from anaesthesia was very smooth and all the dogs recovered completely within 3-4 hours following surgery. No any anaesthetic complications or anaesthetise emergencies were observed in any dog. Gupta (2005), Bhagat (2009) reported successful use of ketamine and midazolam combination for induction and maintenance of anaesthesia during orthopaedic procedures in canine.

\section{Surgical procedure for plate Rod Construct}

For fractures of humerus, incision was taken at cranio-lateral border of the humerus. In case of humoral fractures, there are chances of radial nerve damage due to injury by fractured fragments as the location of humerus is closer to brachial plexus. In the present study, this complication was not observed. This approach was found suitable for humerus and there was sufficient exposure of muscles and bone. This made it possible to perform the operative procedure, without any difficulty. The pin insertion in the bone was done properly without any complication. The bone plate placed on cranio-lateral tensile surface of bone had given full rigidity to the assembly in the fixation of fractures of humerus and there was no any tension over the muscle and skin sutures.

The cranio-lateral approach for femur provided the sufficient space for exposure of muscles and bone. The insertion of pin was performed without any complications. Guillemot et al., (2002) reported that, if the pin is inserted in retrograde fashion, there are chances of injury to sciatic nerve.

Table.1 A total of 8 clinical cases of dogs of long bone fractures were treated with plate rod construct

\begin{tabular}{|l|l|l|l|l|l|}
\hline Case No. & Breed & $\begin{array}{l}\text { Age in } \\
\text { years }\end{array}$ & Sex (M/F) & $\begin{array}{l}\text { Bone } \\
\text { affected }\end{array}$ & Type of fracture \\
\hline $\mathbf{1}$ & Mongrel & 0.8 & $\mathrm{~F}$ & Femur & Transverse at distal shaft \\
\hline $\mathbf{2}$ & Mongrel & 4.0 & $\mathrm{M}$ & Femur & Transverse at mid shaft \\
\hline $\mathbf{3}$ & Mongrel & 2.0 & $\mathrm{M}$ & Humeurs & Oblique at mid shaft \\
\hline $\mathbf{4}$ & Mongrel & 1.0 & $\mathrm{M}$ & femur & Oblique at mid shaft \\
\hline $\mathbf{5}$ & Mongrel & 2.5 & $\mathrm{M}$ & Humeurs & $\begin{array}{l}\text { Comminuted lower mid } \\
\text { shaft }\end{array}$ \\
\hline $\mathbf{6}$ & $\begin{array}{l}\text { German } \\
\text { Shepherd }\end{array}$ & 1.0 & $\mathrm{~F}$ & Femur & Comminuted distal shaft \\
\hline $\mathbf{7}$ & Mongrel & 1.5 & $\mathrm{M}$ & Femur & Comminuted at mid shaft \\
\hline $\mathbf{8}$ & Mongrel & 0.7 & $\mathrm{M}$ & Femur & Oblique at mid shaft \\
\hline
\end{tabular}


Fig.1 Preparation of site in the dog having fracture of left humerus

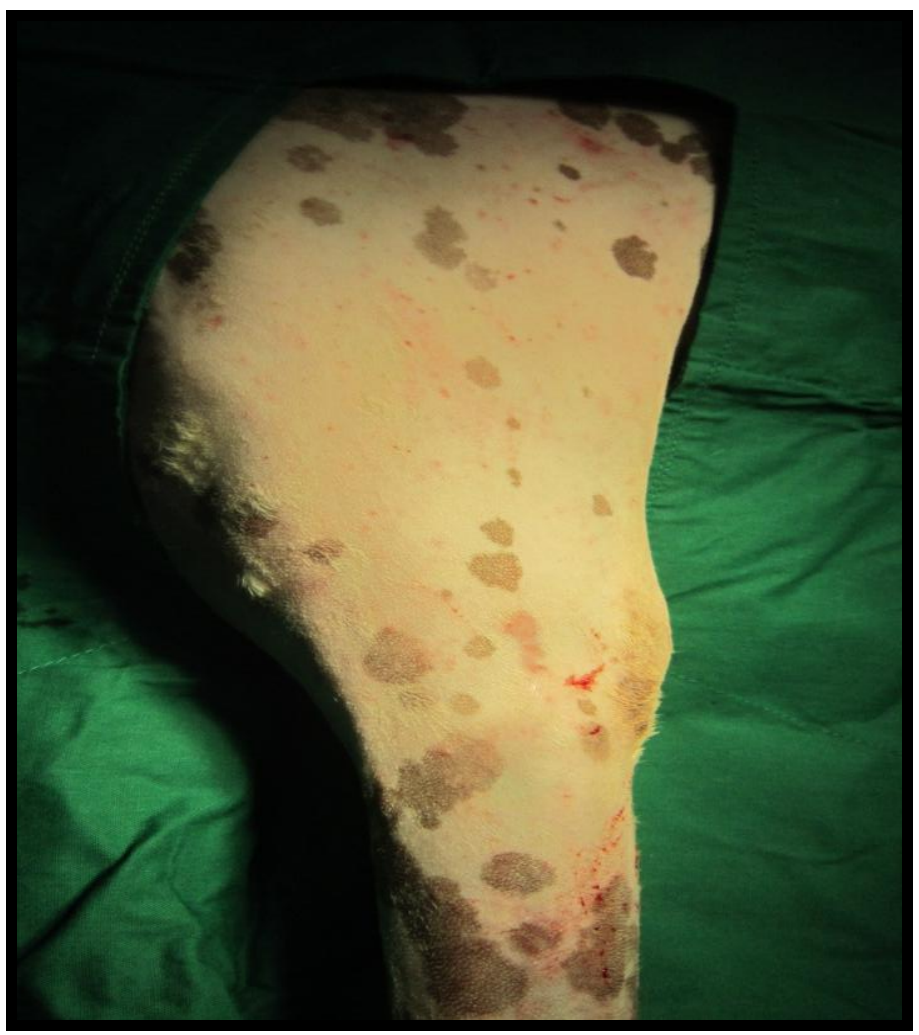

Fig.2 Complete removal of previous soft callus over bone fragments and freshened bone fragments

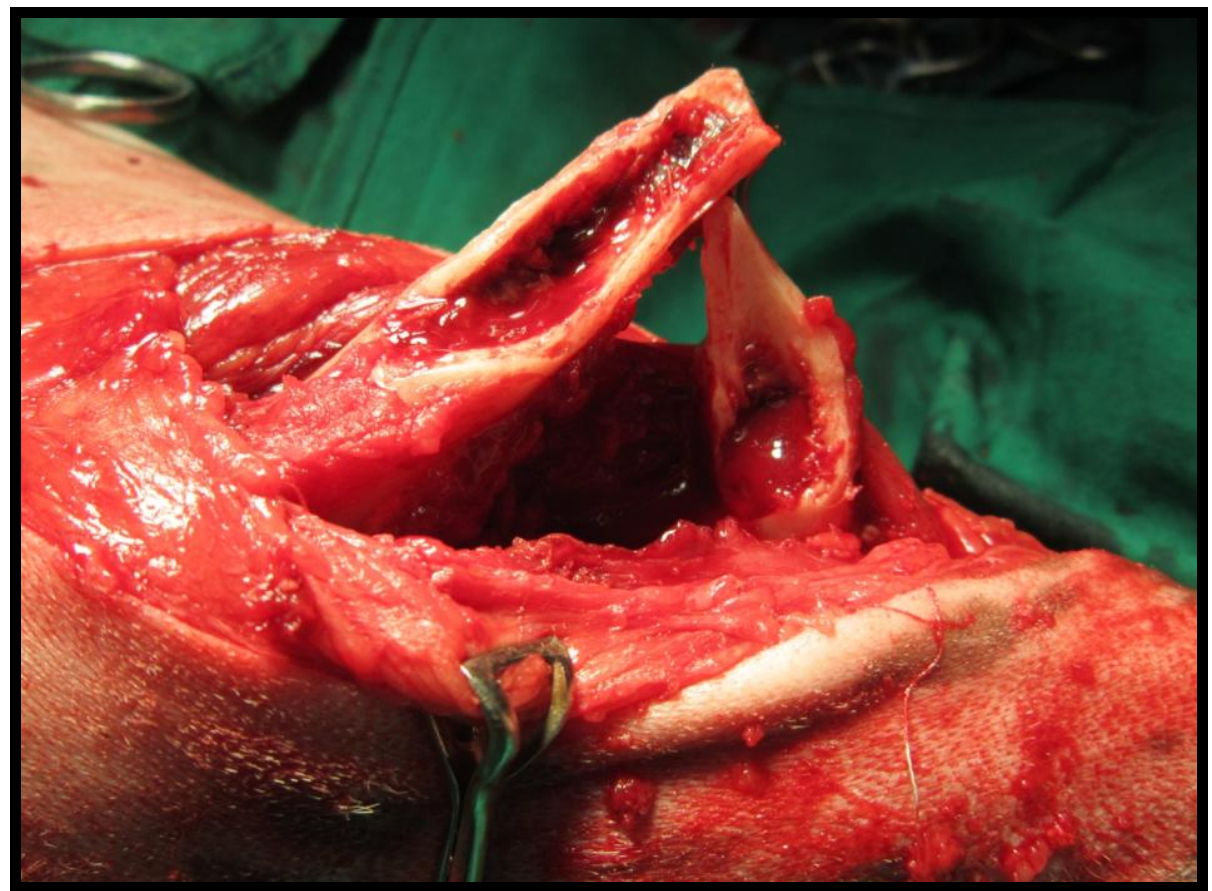


Fig.3 Retrograde insertion of intramedullary pin

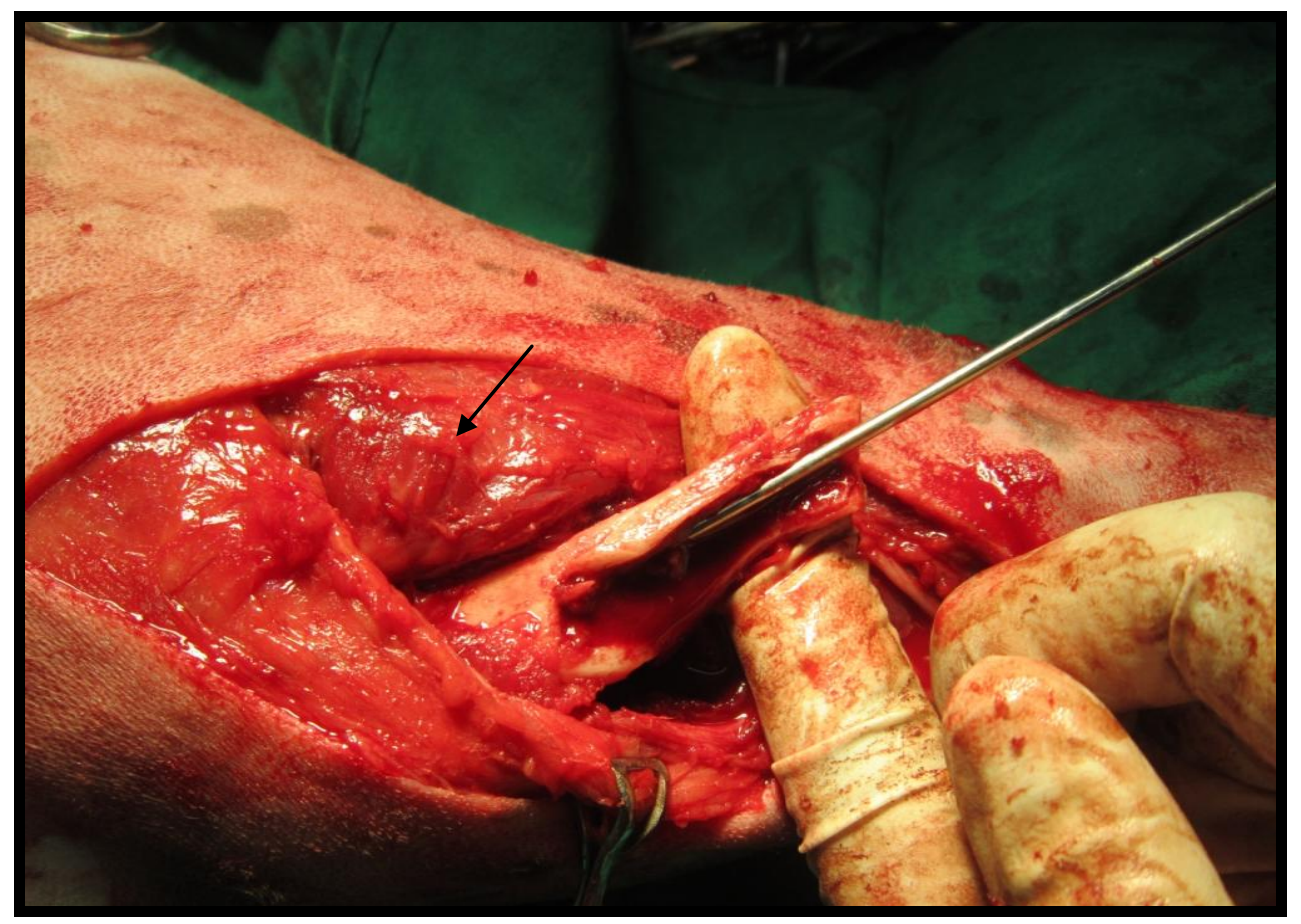

Fig.4 Placement of bone plate on anteriolateral tensile surface of humerus and drilling of screw holes

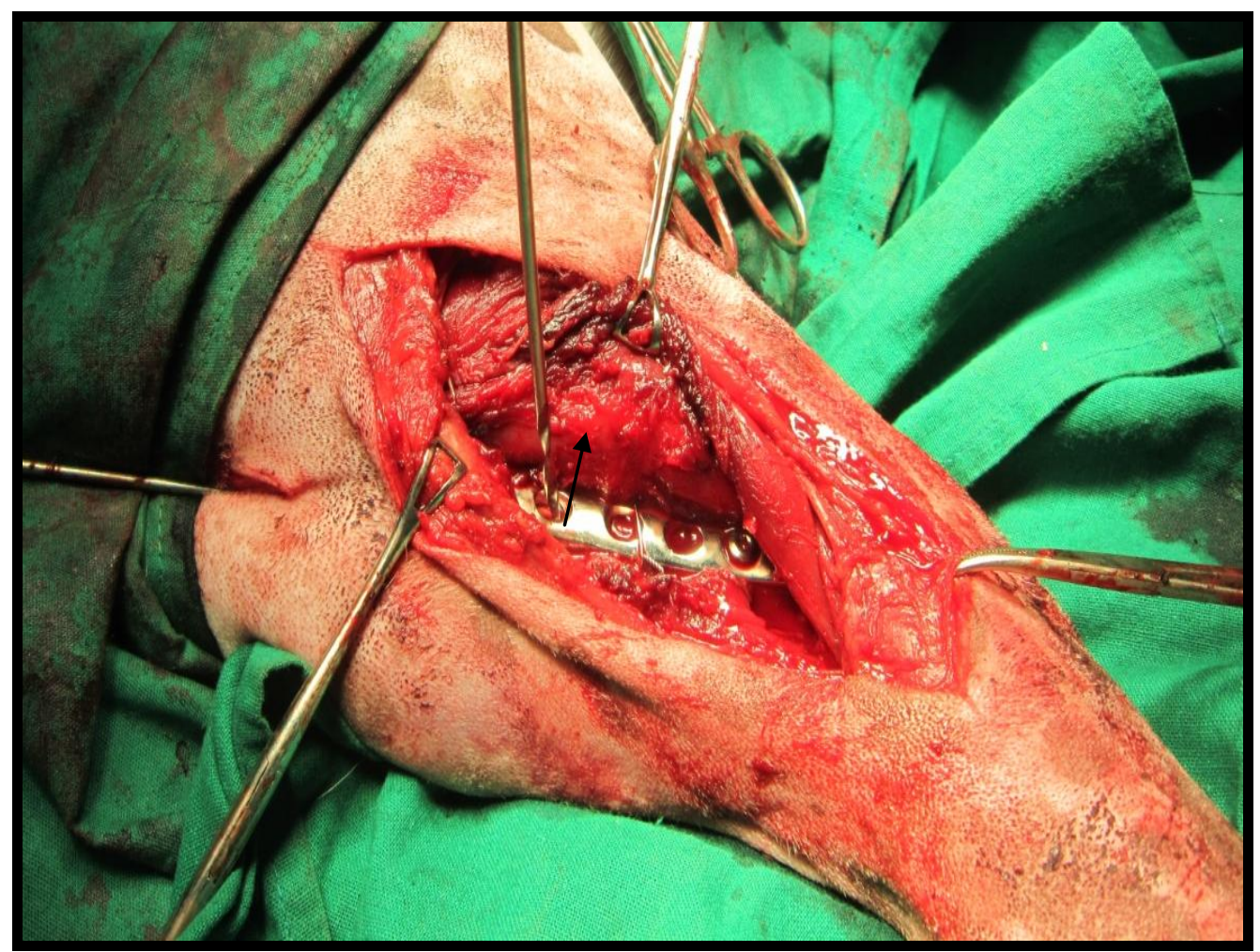


Fig.5 Bone plate and intramedullary pin in position in plate rod construct

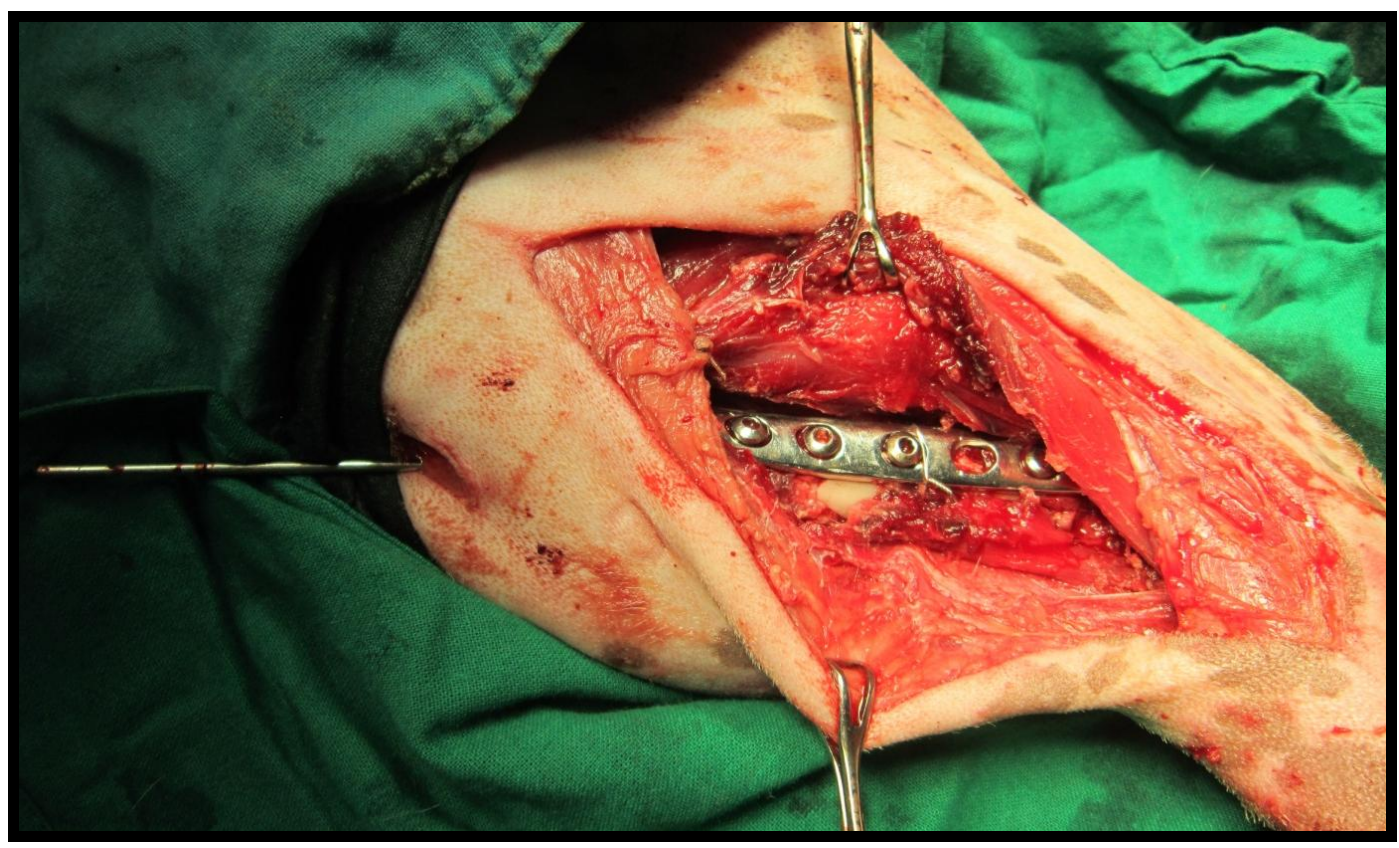

In present study the stainless steel bone plate of $2.7-3.5 \mathrm{~mm}$ size and of appropriate length and proper size screws were used for the fixation of plate, while intramedullary pin or K-wire of 25 to $40 \%$ of the diameter of medullary canal $(2.0 \mathrm{~mm}-2.5 \mathrm{~mm})$ was used for intramedullary fixation. If intramedullary pin or K- wire of bigger than $40 \%$ diameter of medullary cavity would have been used, then it would not have been possible to use all bicortical screw fixation. This has given very stable fixation of fracture in all the cases. Bhalerao (2010) used the similar types of intramedullary pins and bone plates for the repair of canine long bone fractures. Rigidity of a bone plate by combining the strength of plate rod construct.

The intramedullary pin or K-wire of $2.0-2.5$ $\mathrm{mm}$ diameter $(25-40 \%)$ was inserted in retrograde fashion till it come out at the top of the skin surface and then the pin was moved down through normo-grade fixation into the distal femoral or humoral fragment. This insertion of intramedullary pin or K- wire helped in gaining of proper length and strength to the bone with proper alignment of bone fragments. Following proper fracture reduction and alignment of fracture, the application of low man's clamp and bone plate was very much essential for proper insertion of intramedullary pin into the distal fractured fragments. While drilling of holes for the placement of screws, the drill bit struck over the intramedullary pin or K- wire, under such situation slight changing of angle of drilling allowed easy insertion of drill bit through the far cortex of bone.

Fixation of bone plate with at least two screws near the fracture and one in corner hole of the plate on either side was done without difficulty. Initially placement of bicortical screws to each corner of hole of plate requires practical experience to avoid its entry at site of intramedullary pin. This could be learned once surgeon gets an idea about the length and depth of intra medullary pin in the medullary cavity. This could be best achieved if one gets advantage of image of $\mathrm{C}$ arm $\mathrm{x}$-ray machine during the time of bicortical screw fixation. 
The combination of intramedullary pin / Kwire and bone plate provided rigid fixation and given strength to plate rod assembly. Ferry et al., (2000) and Roe (2003) stated that the size of intramedullary pin should be 30 $40 \%$ of size of medullary cavity.

\section{Clinical parameters}

\section{Wound healing}

The dogs showed excellent wound healing and none of the dog showed any complications after surgery. Second intension or mixed intension healing was observed in all the remaining cases that were presented quiet late for fracture immobilization. Similar results were reported in late presented cases of fracture by Lokhande (1989), and Coutinho (2012)

\section{Gait}

Shortest period of $12.8 \pm 2.3$ days was required to attain normal gait for all the dogs, except one. In one dog more time to attain normal gait was because of accidental injuries as a result pin migration. Ayappan et al., (2011) reported normal gait and weight bearing shortly following plate rod fixation.

\section{Change in shape of limb}

On day $10,20,30^{\text {th }}$ and $60^{\text {th }}$ day remained normal in all the animals of all the groups. Normal shape of limb after fracture healing could be due to maintenance of normal muscle mass and physiological movement of limb (Yadav et al., 2006).

\section{Time required for clinical healing of fracture}

Was $62.25 \pm 2.25$ days. Time required to attaining full mobility, was recorded Similar findings are reported following repair of fracture by plate rod construct and bone plating by Bhalerao (2010) and Chavan (2013).

\section{Time required to attaining full mobility}

Was $58.75 \pm 6.67$ days Ayappan et al., (2011) reported similar results in plate rod construct.

\section{References}

Ayyappan, S., Shiju S. M., Das B. C. 2, Prasad A. A. and Suresh Kumar, R. (2011) Management of diaphyseal humeral fracture using plate rod technique in a dog. Tamilnadu J. Veterinary \& Animal Sciences 7 (1): 35-38.

Bhagat, V. T. (2009) Evaluation of limited contact dynamic compression plating for correction of diaphyseal fractures of long bones in dogs. M. V. Sc. thesis submitted to Tamil Nadu Veterinary and Animals Sciences University.

Bhalerao, D. V. (2010) Comparative studies on plate-rod construct and bone plating for long bone fractures in canines. Unpublished M. V. Sc. Thesis submitted to Maharashtra Animal and Fisheries Sciences University, Nagpur, Maharashtra.

Chavan, S. R. (2013) Evaluation of locking compression plate system for long bone fracture repair in dogs: A clinical study. M. V. Sc. thesis submitted to Maharashtra Animal and Fishery Sciences University, Nagpur, India.

Coutinho, N. R. (2012) Evaluation of interlocking nail for long bone fracture repair in dogs: a clinical study. Unpublished M. V. Sc. Thesis Maharashtra Animal and Fishery Science University, Nagpur.

Ferry K. A., D. Fawcett, W. Gentry, Hyman, S. Geller and M. Slater (2000) Effect of intramedullary pin size on reducing 
bone plate strain. Vet Comp Ortho Traumatol 13 (4): 185-190.

Guillemot A. E., F. G. Asimus and J. F. Vacher (2002) Biological osteosynthesis of communitted femoral fracture in a cat using a pin/ VCP plate combination. Prat. Med. Chir. Anim. Comp. 37:211-214.

Gupta, P. (2005). Use of interlocking nails for repair of humeral and tibial shaft fractures under image intensifier in dogs. M. V. Sc. thesis submitted to Anand Agricultural University.

Kaur, H. (2011) Studies on locking compression $\mathrm{T}$ plates and cross pinning for fixation of proximal /distal third long bone fractures in canines. M. V. Sc. thesis submitted to Guru Anged Dev Veterinary and Animal Sciences University, Ludhiana, India.

Konning T. R. J, N. Maarschalkerwerd, L. F. H. Endenburg and Theyse (2008) A comparison between the fixation methods of femoral diphyseal fractures in cats-A retrospective study on 106 cases downloaded from http//igiturarchive.library.uu.nl/student theses/2009-0225-01604 / Manuscript $\% 20$ T. Konning. doc.

Lokhande, D. U. (1989) Experimental studies on use of buffalo horn plates for tibial fracture in buffalo bull calves and its comparison with Stainless Steel plates. Unpublished M. V. Sc. Thesis submitted to Konka Krishi Vidyapeeth, Dapoli.

Newton and Nanumaker (1985) The text book of Small Animal Orthopedics, Charles D. Newton and David M. Nunamaker (ed), J. B. Lippincott company, Philadelphia: 244-245, 373-379.

Rani, (2008) Evaluation of the effect of ultrasound and electrical stimulation for the enhancement of canine femoral fracture healing. Ph. D thesis submitted to Tamilnadu Veterinary and Animal Sciences University, Chennai. India.

Roe, S. (2004). Internal fracture fixation. In: Textbook of Small Animal Surgery, Slatter, D. H. 3rd Ed, Vol. II. WB Saunders, Philadelphia. Pp: 1798-1818.

Stifler, K. S. (2004) Internal fracture fixation. Clin Tech Small Anim Pract 19(3): 105113.

Yadav R. K., M. Raghunath and S. S. Singh (2006) Static Interlocking nailing for management of complicated femur fracture in dogs. Ind. J. Vet. Surg. 27(2): 113-115

\section{How to cite this article:}

Yadav G. U., L. B. Sarkate and Lokhande D. U. 20212. Clinical Studies on Treatment of Long Bone Fracture by the Use of Plate Rod Construct. Int.J.Curr.Microbiol.App.Sci. 10(04): 778786. doi: https://doi.org/10.20546/ijcmas.2021.1004.080 